\title{
ENHANCED PHOTODEGRADATION OF METHYLENE BLUE AND CRYSTAL VIOLET USING NANO ZnO UNDER DIRECT SUNLIGHT
}

\author{
Pola Jeevan Kumar', R. Hemachander², R.K. Praveen², C. Hariram², \\ P.S. Raghavan ${ }^{1}$ and S. Induja ${ }^{1, \bigotimes}$ \\ ${ }^{1}$ Department of Chemistry, Hindustan Institute of Technology and Science, \\ Chennai - 603103, (Tamil Nadu) India \\ ${ }^{2}$ Department of Chemical Engineering, Hindustan Institute of Technology and Science, \\ Chennai - 603103, (Tamil Nadu) India \\ Corresponding Author: sinduja@hindustanuniv.ac.in
}

\begin{abstract}
The paper investigates the degradation of methylene blue and crystal violet in the presence of direct sunlight using nano zinc oxide as a photocatalyst. The zinc oxide nanoparticles were prepared using precipitation and sonochemical methods and characterized using XRD, SEM and BET techniques. The photodegradation studies were carried out in a batch reactor in the presence of direct sunlight. The influence of catalyst content and $\mathrm{pH}$ of the solution, on the dye degradation, were studied and optimized. The results revealed that the optimized catalyst exhibited $96 \%$ dye degradation in 25 minutes of reaction time.
\end{abstract}

Keywords: Dye Degradation, Nano ZnO, Photocatalyst, Methylene Blue, Crystal Violet.

RASĀYAN J. Chem., Vol. 14, No.2, 2021

\section{INTRODUCTION}

The dyeing industries generally discharge nearly 200,000 tons of dyes worldwide into the effluent annually. ${ }^{1}$ In addition to pollution, the disposal of these effluents into the water bodies leads to eutrophication thereby creating an imbalance in the aquatic ecosystem. The inefficiency of the conventional wastewater treatment to completely degrade the dyes has drawn the attention of alternate technologies in recent years. The advanced oxidation process is an eco-friendly and cost-effective alternative in textile effluent treatment. Photocatalysis involving semiconducting materials such as $\mathrm{TiO}_{2}$, $\mathrm{ZnO}$ and their composites are reported to degrade the dyes completely. ${ }^{2-6}$ Oxidation of organic pollutants employing semiconductor type photocatalyst is well known and involves excitation of electrons from the valence to the conduction band resulting in the generation of electron-hole pair. The higher oxidative potential of the positive hole is responsible for the oxidation of water leading to the generation of $\bullet \mathrm{OH}$ radicals. Thus, the hydroxyl radicalsdegrade the organic dye. Among the various photocatalysts, $\mathrm{ZnO}$ is a potential catalytic material due to its high photosensitivity, non-toxic, high stability with a bandgap of $3.37 \mathrm{eV}$, low cost, easy availability and absorbs a large fraction of solar spectrum. ${ }^{7}$ Mostly, literature reports the degradation of methylene blue and crystal violet using zinc oxide in the presence of UV or another irradiation source (Table-1). Eventhough a few reviews on the dye degradation are reported in the visible region, it generally involves longer conversion time and inconvenient working $\mathrm{pH}$ range, i.e., highly acidic or alkaline conditions during which the dissolution of $\mathrm{Zn}^{2+}$ takes place resulting in reduced photocatalytic activity. Therefore, the paper investigates the efficient method for preparing nano zinc oxide for the degradation of methylene blue and crystal violet under sunlight thereby providing a simple and cost-effective solution.

\section{EXPERIMENTAL}

The nano zinc oxidewas synthesized using chemical precipitation and sonochemical methods. The precipitation method involves dissolving a calculated quantity of zinc acetate dihydrate (99\%) in distilled

Rasayan J. Chem., 14(2), 719-727(2021)

http://dx.doi.org/10.31788/ RJC.2021.1426176 
RASĀYAN J. Chem.

Vol. 14 | No. 2 |719-727| April - June | 2021

water. The solution of ammonium carbonate (30\% as ammonia) was added dropwise to the above solution. The suspension was continuously stirred for $2 \mathrm{~h}$ and allowed to stand overnight. Later the precipitate was filtered, washed and dried at $120^{\circ} \mathrm{Cfor} 2 \mathrm{~h}$. The dried samples were calcined at $450^{\circ} \mathrm{C}$ for $3 \mathrm{~h}$ and labeled as $\mathrm{ZnO} / \mathrm{CAR}$. The second catalyst was prepared using sodium hydroxide as the precipitating agent. The precipitate obtained was filtered and washed repeatedly using distilled water and ethanol. The precipitate was dried at $120^{\circ} \mathrm{C}$ for $2 \mathrm{~h}$ and calcined at $450^{\circ} \mathrm{C}$ for $3 \mathrm{~h}$ and the sample was labeled as $\mathrm{ZnO} / \mathrm{NaOH}$.

Table-1: Degradation of Methylene Blue and Crystal Violet (From Literature).

\begin{tabular}{c|c|c|c|c|c|c}
\hline Photocatalyst & $\begin{array}{c}\text { Catalyst } \\
\text { Amount }\end{array}$ & Particle Size & $\begin{array}{c}\text { Conc. of } \\
\text { Dye, ppm }\end{array}$ & Source & \multicolumn{1}{c|}{$\begin{array}{c}\text { Time } \\
(\mathrm{min})\end{array}$} & Ref. \\
\hline \multicolumn{7}{c}{ Degradation of Methylene Blue Dye } \\
\hline $\begin{array}{c}\mathrm{SnS}_{2-} \\
\mathrm{SiO}_{2} @ \alpha \mathrm{Fe}_{2} \mathrm{O}_{3}\end{array}$ & $40 \mathrm{mg}$ & $\begin{array}{c}20 \mathrm{~nm}-\mathrm{SiO}_{2} ; 150 \\
\mathrm{~nm}-\alpha \mathrm{Fe}_{2} \mathrm{O}_{3}\end{array}$ & 5 & $\begin{array}{c}\text { LED light } \\
\text { source }\end{array}$ & 100 & 8 \\
\hline $\mathrm{RGO} / \mathrm{ZnO}$ & $10 \mathrm{mg}$ & $\begin{array}{c}\text { Crystallite size } 43.4 \\
\mathrm{~nm}\end{array}$ & 5 & UV radiation & 60 & 9 \\
\hline $\mathrm{ZnO}$ & $300 \mathrm{mg}$ & $20-50 \mathrm{~nm}$ & 33 & $\begin{array}{c}400 \mathrm{~W} \\
\text { Krypton lamp }\end{array}$ & 60 & 10 \\
\hline $\mathrm{Au} \mathrm{doped} / \mathrm{TiO}_{2}$ & $50 \mu \mathrm{L}$ & $15-20 \mathrm{~nm}$ & - & $\begin{array}{c}150 \mathrm{~W} \\
\text { tungsten lamp }\end{array}$ & 180 & 11 \\
\hline \multicolumn{7}{|c|}{ Degradation of Crystal Violet Dye } \\
\hline $\mathrm{BiVO} / \mathrm{FeVO}$
\end{tabular}

The sonochemical method of zinc oxide preparation involves dissolving zinc acetate in $0.1 \%$ CTAB solution followed by sonication for 2-3 minutes. During sonication, an aqueous solution of ammonium carbonate was added dropwise and sonication was continued for 10 minutes. The suspension was allowed to settle and the precipitate was filtered, washed repeatedly using distilled water and ethanol and dried at $120^{\circ} \mathrm{C}$. The dried samples were calcined at $450^{\circ} \mathrm{C}$ for $3 \mathrm{~h}$ and the catalyst was labeled as $\mathrm{ZnO} / \mathrm{CAR} / \mathrm{S}$.

The XRD data was recorded in $2 \theta$ range of 20 to 80 at a scan rate of 0.5 degrees per minute with the continuous rotation of the sample during the scan. The morphology of the prepared catalysts was analyzed using a Hitachi Tabletop scanning electron microscope. The BET surface area of the catalysts was determined using Micromeritics ASAP 2020/USA.

\section{Photocatalytic Activity Studies}

The degradation studies on methylene blue and crystal violet dyes were carried out separately in the batch reactor under direct sunlight (Fig.-1). Initially, the calculated quantity of the catalyst was added to 100 $\mathrm{mL}$ of dye solution taken in a $500 \mathrm{~mL}$ beaker. This suspension was kept under stirring for 30 minutes in dark, to attain equilibrium. Later the dye degradation was carried out in the presence of direct sunlight. At regular intervals, $5 \mathrm{ml}$ aliquots of the reaction mixture were removed and centrifuged. The decrease in dye concentration was monitored using Systronics-2202 double-beam UV-Visible spectrophotometer. The percentage dye degradation is calculated by considering the difference in the absorbance of the dye at 0 min and the decrease in the absorbance at time, ' $t$ '. For comparison, the reaction was carried out in the absence of the catalyst. The influence of the catalyst loading at different concentrations of dye was studied following the above procedure. Similarly, the effect of $\mathrm{pH}$ on the dye degradation was studied by adding either dilute $\mathrm{HCl}$ or dilute $\mathrm{NaOH}$ to the reaction mixture.

\section{RESULTS AND DISCUSSION}

The XRD peaks of the catalysts prepared by different methods are presented in Fig.-2. The peaks observed at $31.7,34.3,36.2,47.5,56.5,62.8,68.4$ and 68.8 confirm the formation of ZnO (JCPDS No.89-1397).

The $\mathrm{ZnO}$ prepared by precipitation method using ammonium carbonate ( $\mathrm{ZnO} / \mathrm{CAR}$ ) was found to be more crystalline compared to that prepared by sonochemical method $(\mathrm{ZnO} / \mathrm{CAR} / \mathrm{S})$ and using $\mathrm{NaOH}$ as the precipitant ( $\mathrm{ZnO} / \mathrm{NaOH})$ (Fig.-2). 
RASĀYAN J. Chem.

Vol. 14 | No. 2 |719-727| April - June | 2021

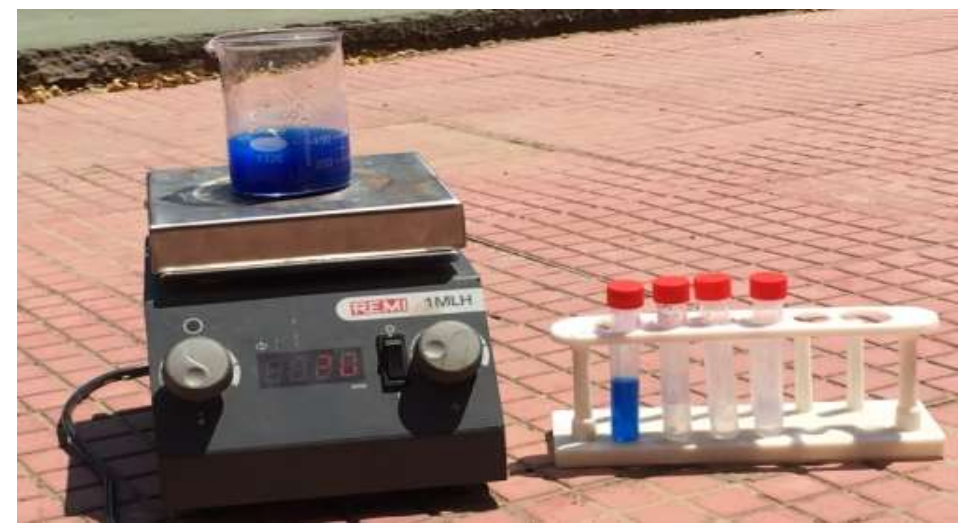

Fig.-1: Experimental Setup
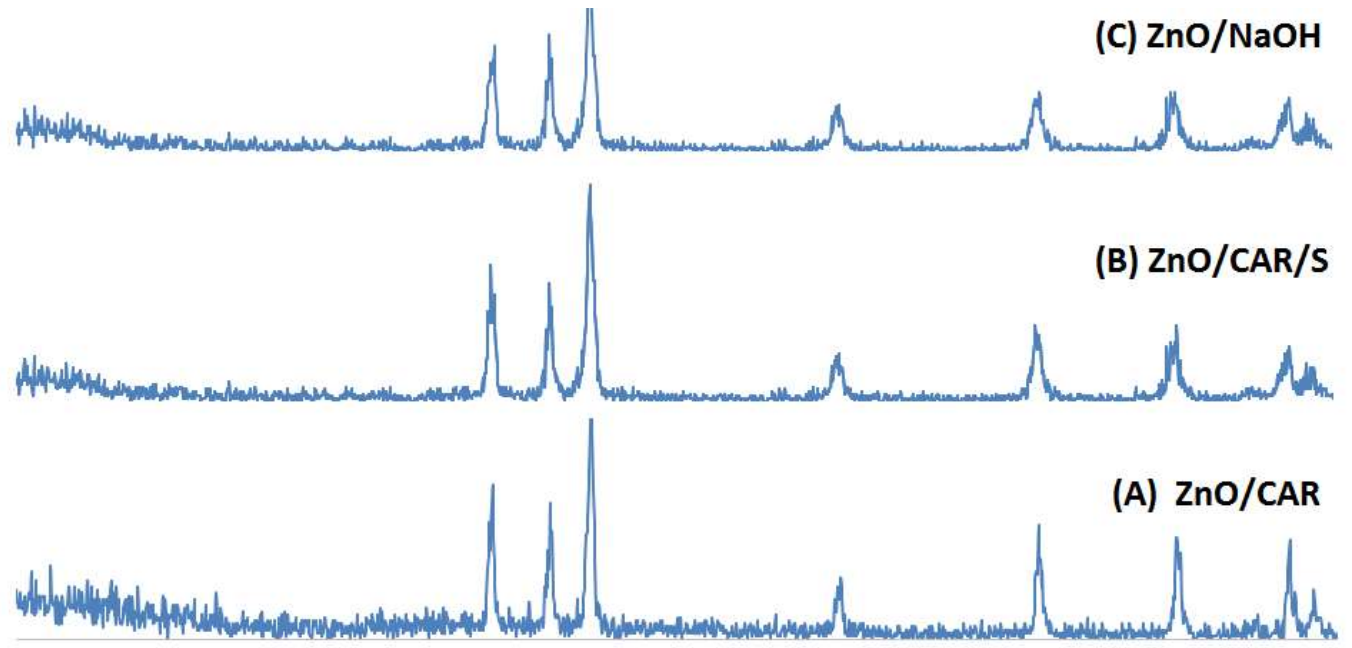

Fig.-2: XRD Patterns of (A) $\mathrm{ZnO} / \mathrm{CAR}$, (B) $\mathrm{ZnO} / \mathrm{CAR} / \mathrm{S}$ and (C) $\mathrm{ZnO} / \mathrm{NaOH}$

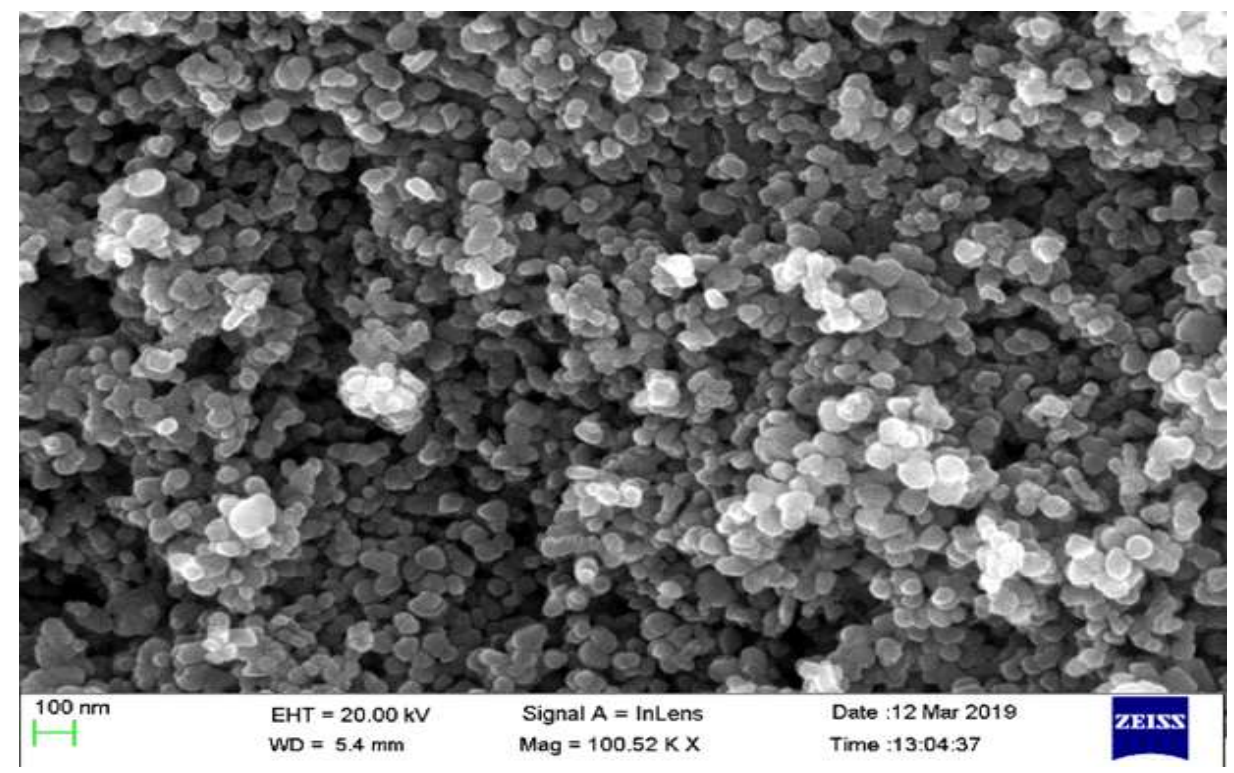

Fig.-3: SEM Image of $\mathrm{ZnO} / \mathrm{CAR}$ Catalyst 
RASĀYAN J. Chem.

Vol. 14 | No. 2 |719-727| April - June | 2021

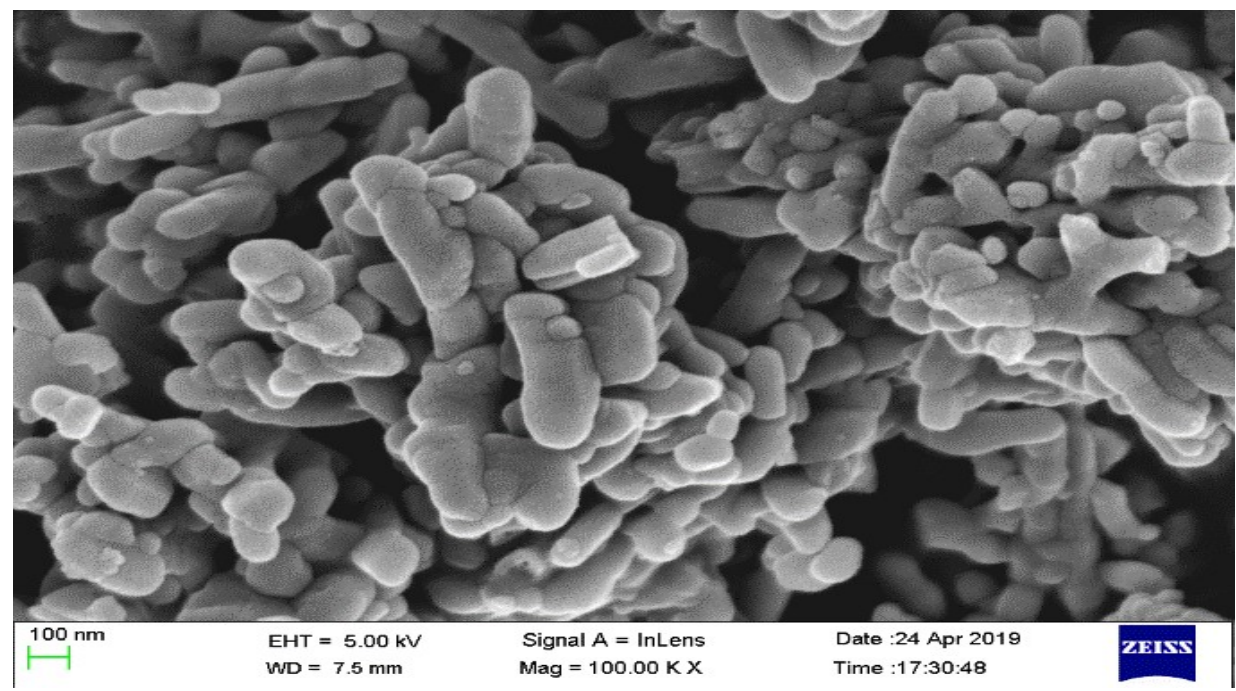

Fig.-4: SEM Image of $\mathrm{ZnO} / \mathrm{NaOH}$ Catalyst

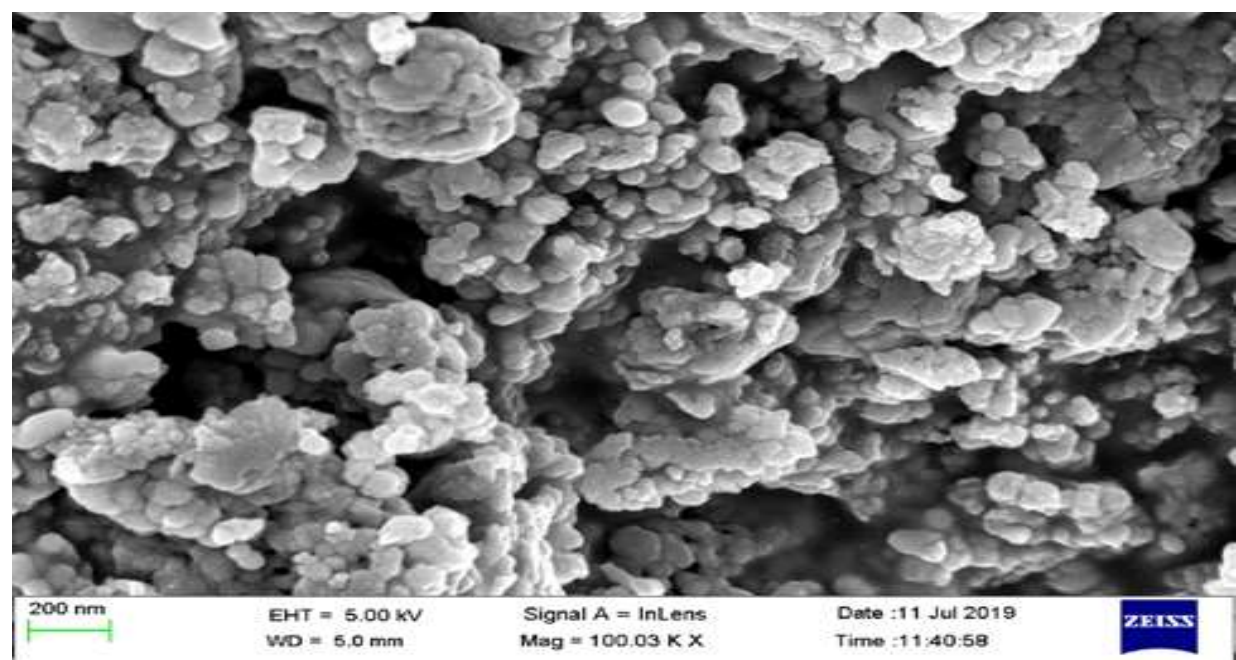

Fig.-5: SEM Image of $\mathrm{ZnO} / \mathrm{CAR} / \mathrm{S}$ Catalyst

The morphology of the $\mathrm{ZnO}$ catalyst prepared using ammonium carbonate was found to be nearly spherical ( $\mathrm{ZnO} / \mathrm{CAR})$, uniformly dispersed and the average particle size was found to be between 20$40 \mathrm{~nm}$ (Fig.-3). The $\mathrm{ZnO}$ catalyst prepared using sodium hydroxide was found to be rod-shaped with a particle size ranging between $70-80 \mathrm{~nm}(\mathrm{ZnO} / \mathrm{NaOH}$, Fig.-4). Whereas, the $\mathrm{ZnO}$ photocatalyst prepared to employ ammonium carbonate as a precipitating agent in the presence of surfactant - CTAB and sonication $(\mathrm{ZnO} / \mathrm{CAR} / \mathrm{S}$, Fig. -5$)$ showed agglomeration of the spherical particles.

The surface area of the $\mathrm{ZnO} / \mathrm{NaOH}$ and $\mathrm{ZnO} / \mathrm{CAR} / \mathrm{S}$ catalyst was found to be $14.8 \mathrm{~g} / \mathrm{m}^{2}$ and $14.4 \mathrm{~g} / \mathrm{m}^{2}$ respectively, while the surface area of the $\mathrm{ZnO} / \mathrm{CAR}$ catalyst was found to be $24.8 \mathrm{~g} / \mathrm{m}^{2}$.

\section{Photocatalytic Degradation of Dye}

Initially, the reaction was carried out for $5 \mathrm{ppm}$ of dye with acidic pH of 4.5. The effect of the catalyst content on the degradation of methylene blue was studied by varying the same in the range $0.05 \mathrm{~g}-0.5 \mathrm{~g}$. The rate of degradation of methylene blue was found to increase with the increase in catalyst weight from $0.05 \mathrm{~g}$ to $0.1 \mathrm{~g}$ and beyond $0.1 \mathrm{~g}$ the rate of degradation was found to be nearly constant (Fig.-6). In the case of crystal violet, the rate of degradation was found to increase with the increase in weight of the catalyst from $0.05 \mathrm{~g}$ to $0.5 \mathrm{~g}$ and beyond $0.5 \mathrm{~g}$ the rate of dye degradation was found to be nearly the same (Fig.-10). Thus, the catalyst loading optimized for methylene blue and crystal violet was $0.1 \mathrm{~g}$ and $0.5 \mathrm{~g}$, respectively. The rate of dye degradation was found to increase with the increase in the amount of catalyst. As reported 
RASĀYAN J. Chem.

Vol. 14 | No. 2 |719-727| April - June | 2021

by earlier researchers, this increase can be attributed to the increase in the availability of the active sites resulting in effective adsorption of dye molecules thereby leading to higher conversion. ${ }^{14}$

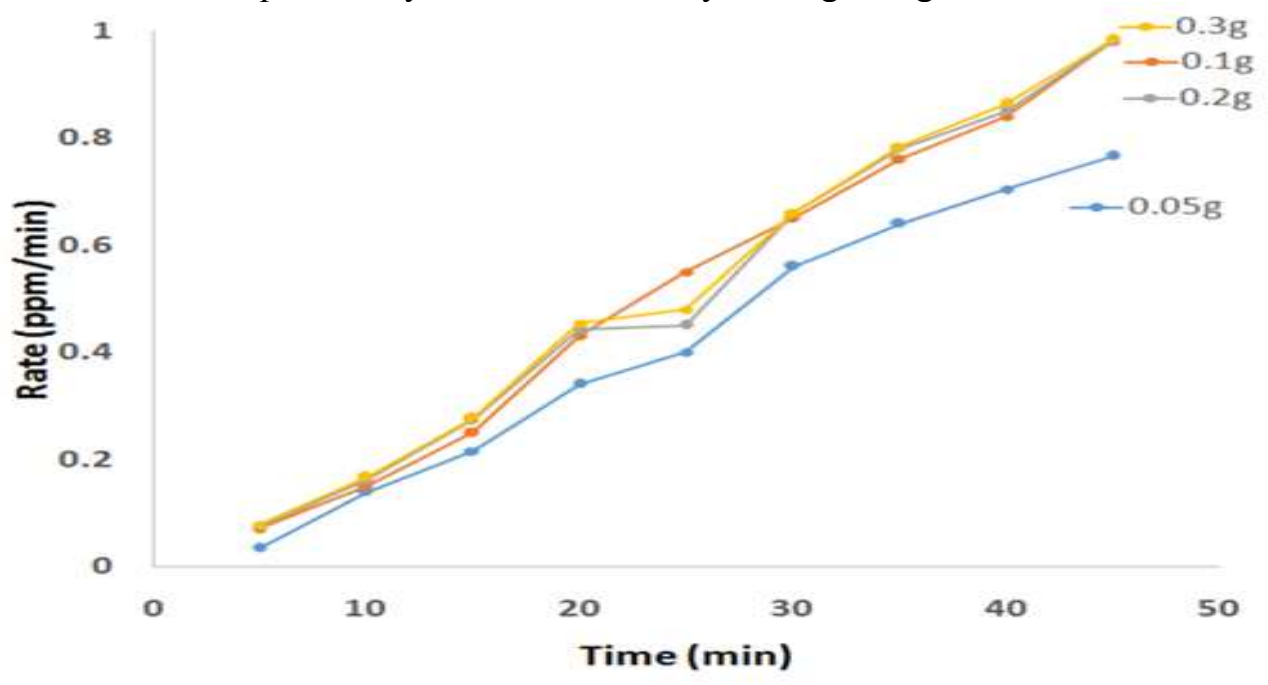

Fig.-6: Influence of Catalyst Content on the Degradation of Methylene Blue at pH 4.5; Rate Vs Time

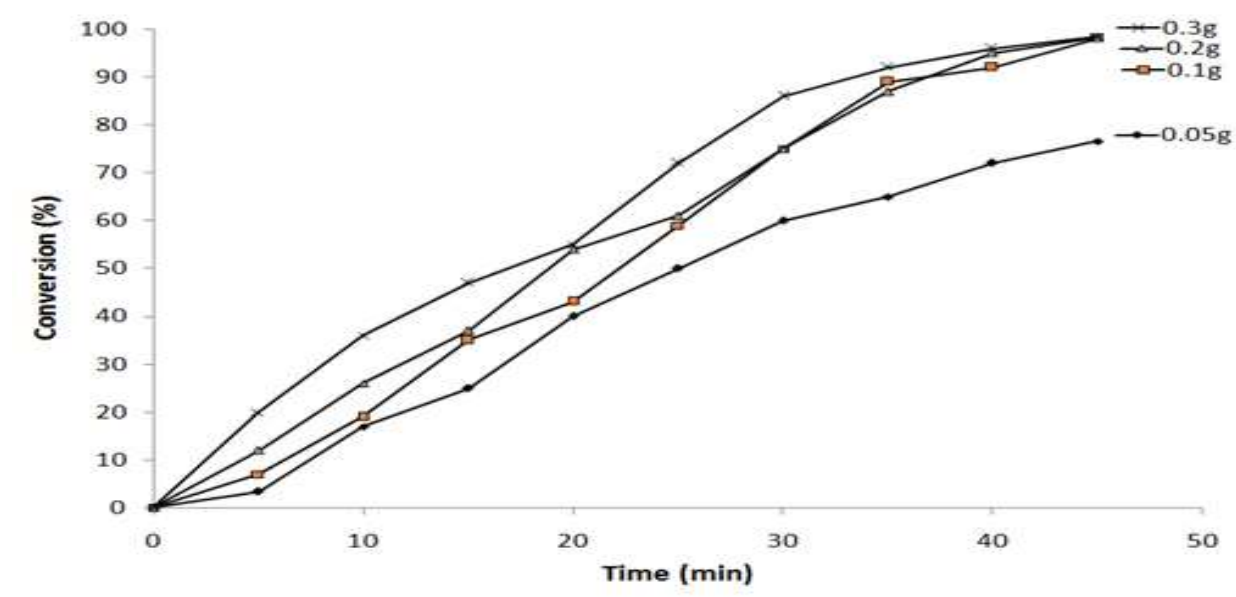

Fig.-7: Influence of Catalyst Content on the Degradation of Methylene Blue at pH 4.5; Conversion over 5ppm of Dye

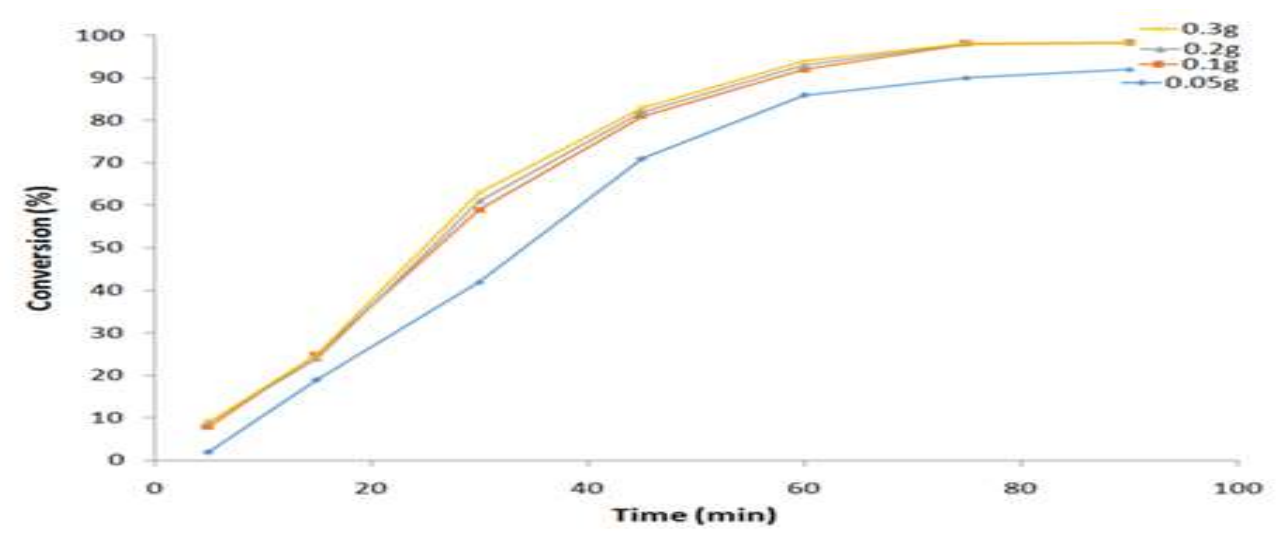

Fig.-8: Influence of Catalyst Content on the Degradation of Methylene Blue at pH 4.5; Dye Content - 10ppm. 
RASĀYAN J. Chem.

Vol. 14 | No. 2 |719-727| April - June | 2021

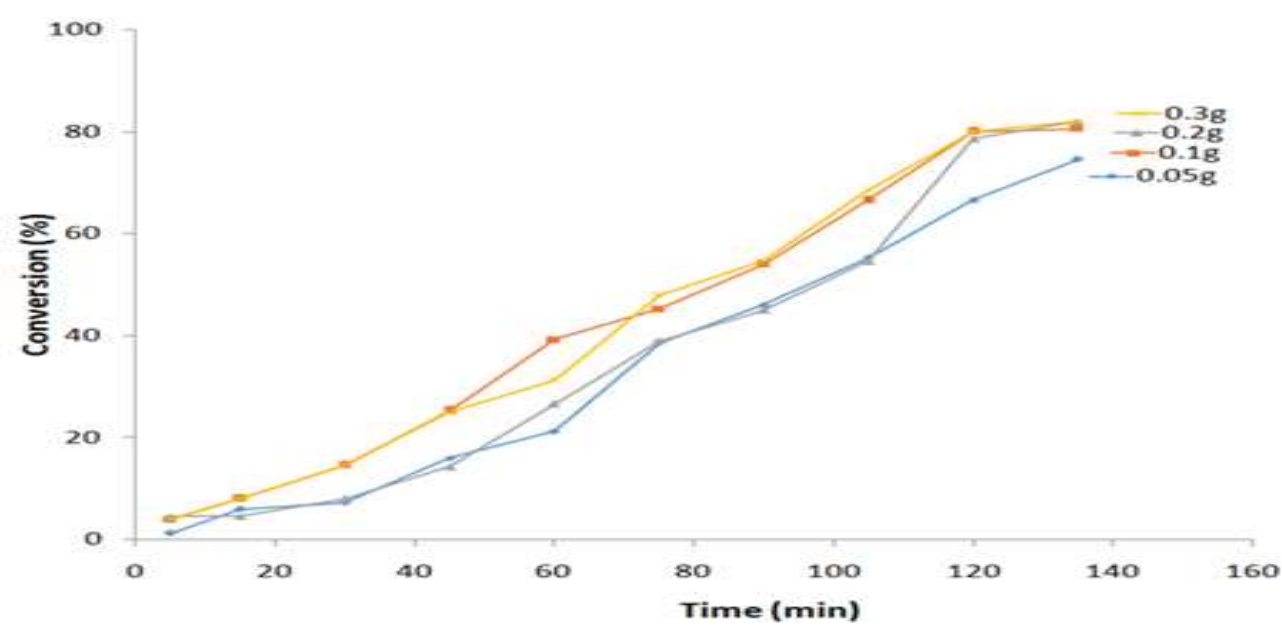

Fig.-9: Influence of Catalyst Content on the Degradation of Methylene Blue at pH4.5; Conversion over 15ppm of Dye

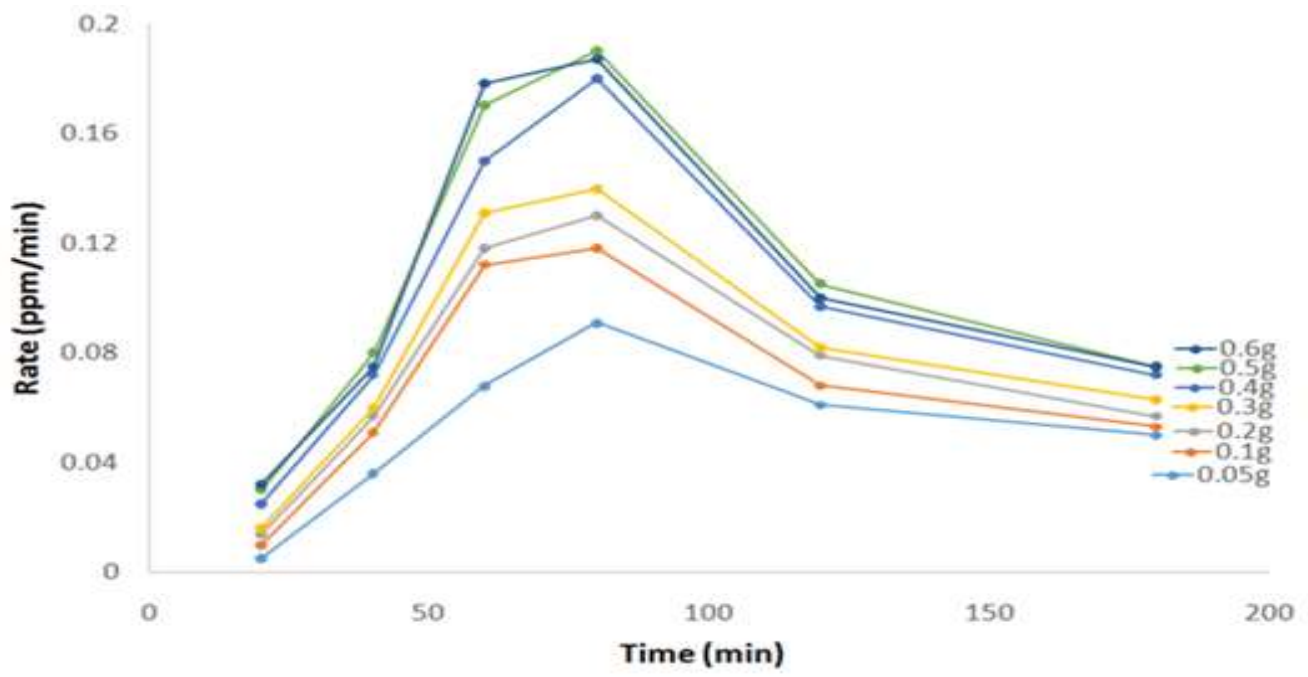

Fig.-10: Influence of Catalyst Content on the Degradation of Crystal Violet at $\mathrm{pH}-4.5$; Rate vs Time

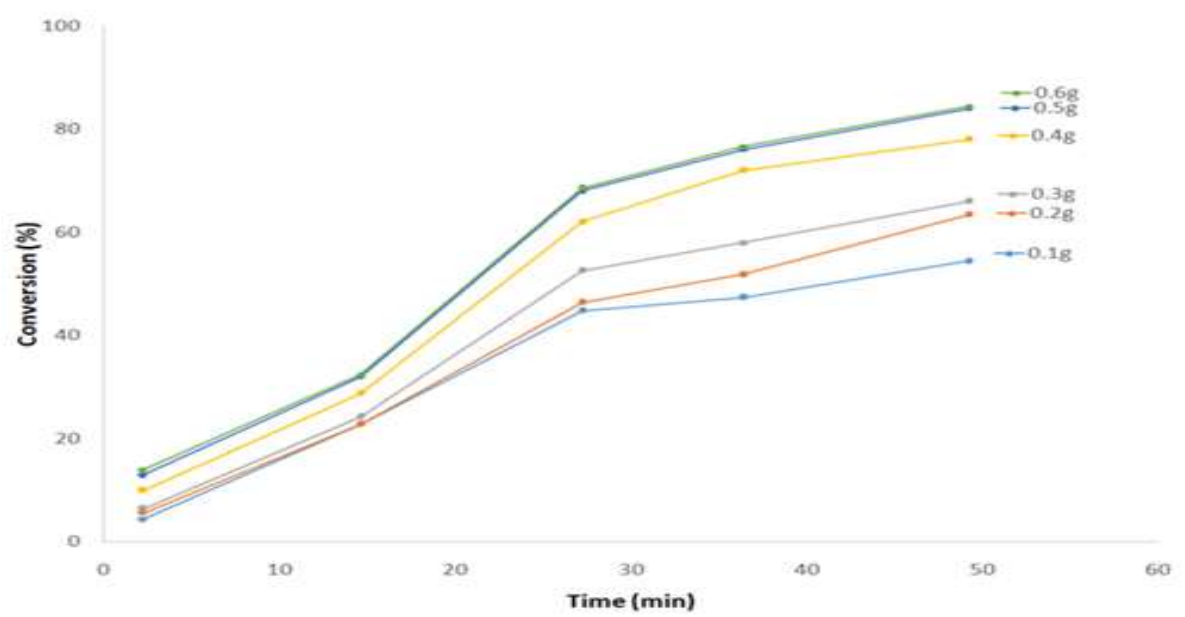

Fig.-11: Influence of Catalyst Content on the Degradation of Crystal Violet at $\mathrm{pH}-4.5$; Conversion over 5ppm of Dye 
RASĀYAN J. Chem.

Vol. 14 | No. 2 |719-727| April - June | 2021

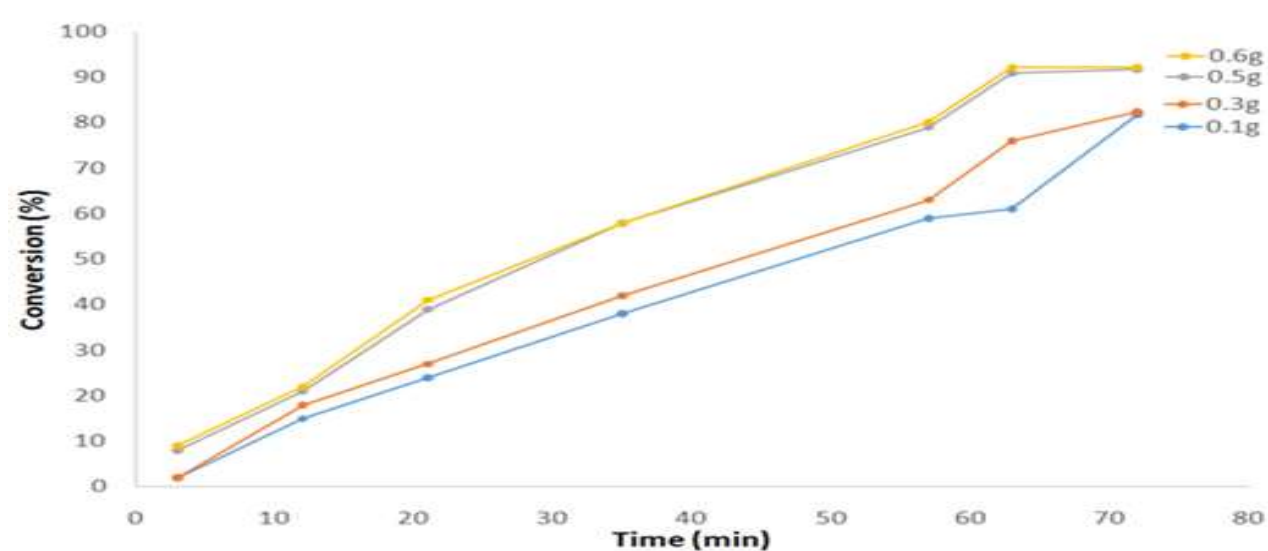

Fig.-12: Influence of Catalyst Content on the Degradation of Crystal Violet at $\mathrm{pH}-4.5$; Conversion over 10ppm of Dye

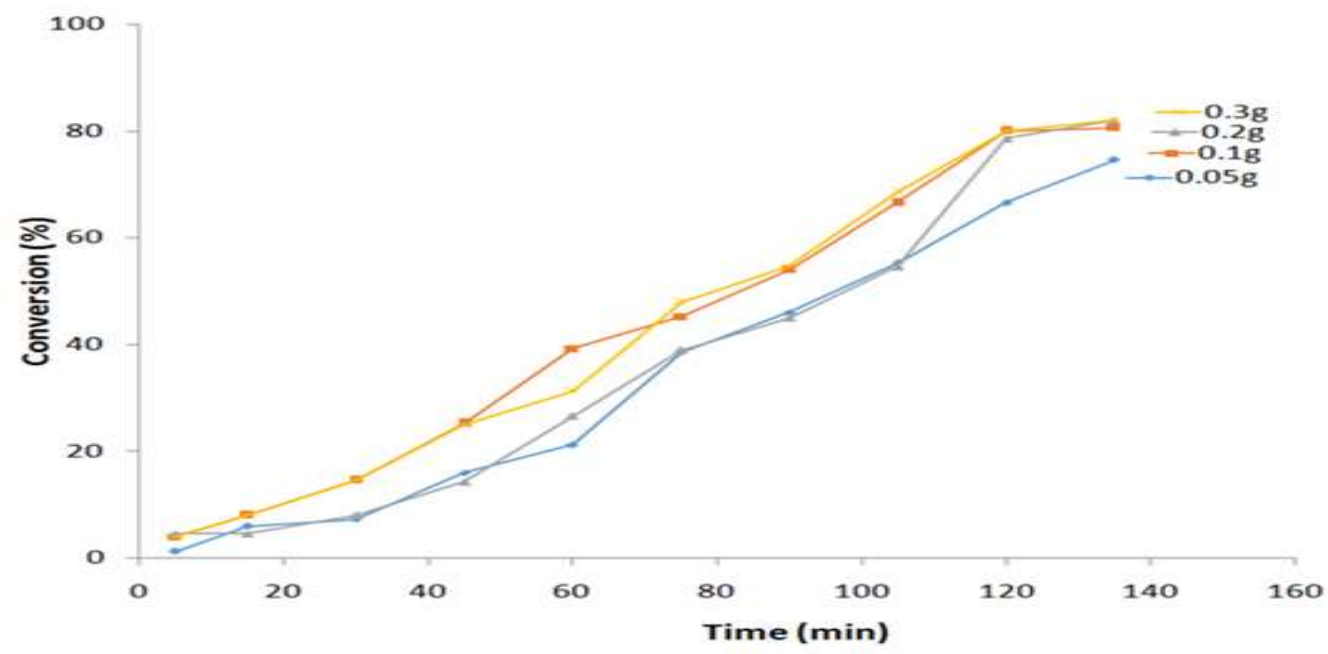

Fig.-13: Influence of Catalyst Content on the Degradation of Crystal Violet at pH -4.5; Conversion over 15ppm of Dye

Beyond the optimized catalyst loading, the excess zinc oxide particles present in the suspension scatter the photons leading to the reduction of photon flux in the suspension. Thus, the rate either remains the same or decreases.

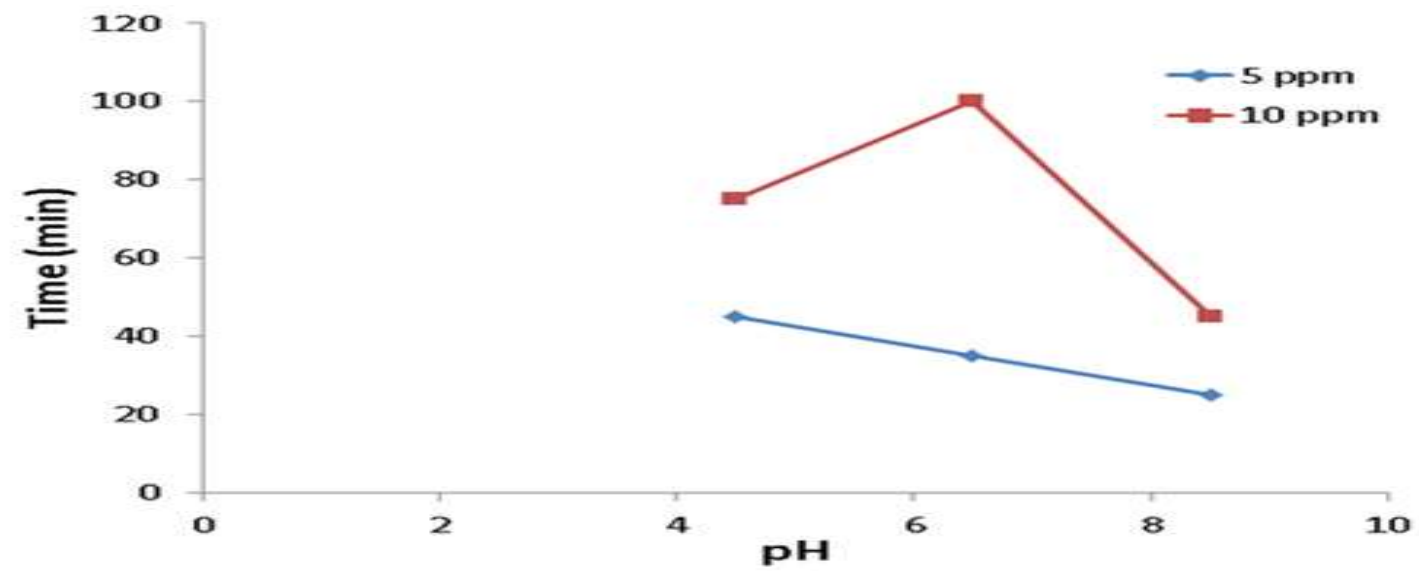

Fig.-14: Influence of $\mathrm{pH}$ on Time taken for $98 \%$ Degradation of Methylene Blue with $0.1 \mathrm{~g}$ of Catalyst 
RASĀYAN J. Chem.

Vol. 14 | No. 2 |719-727| April - June | 2021

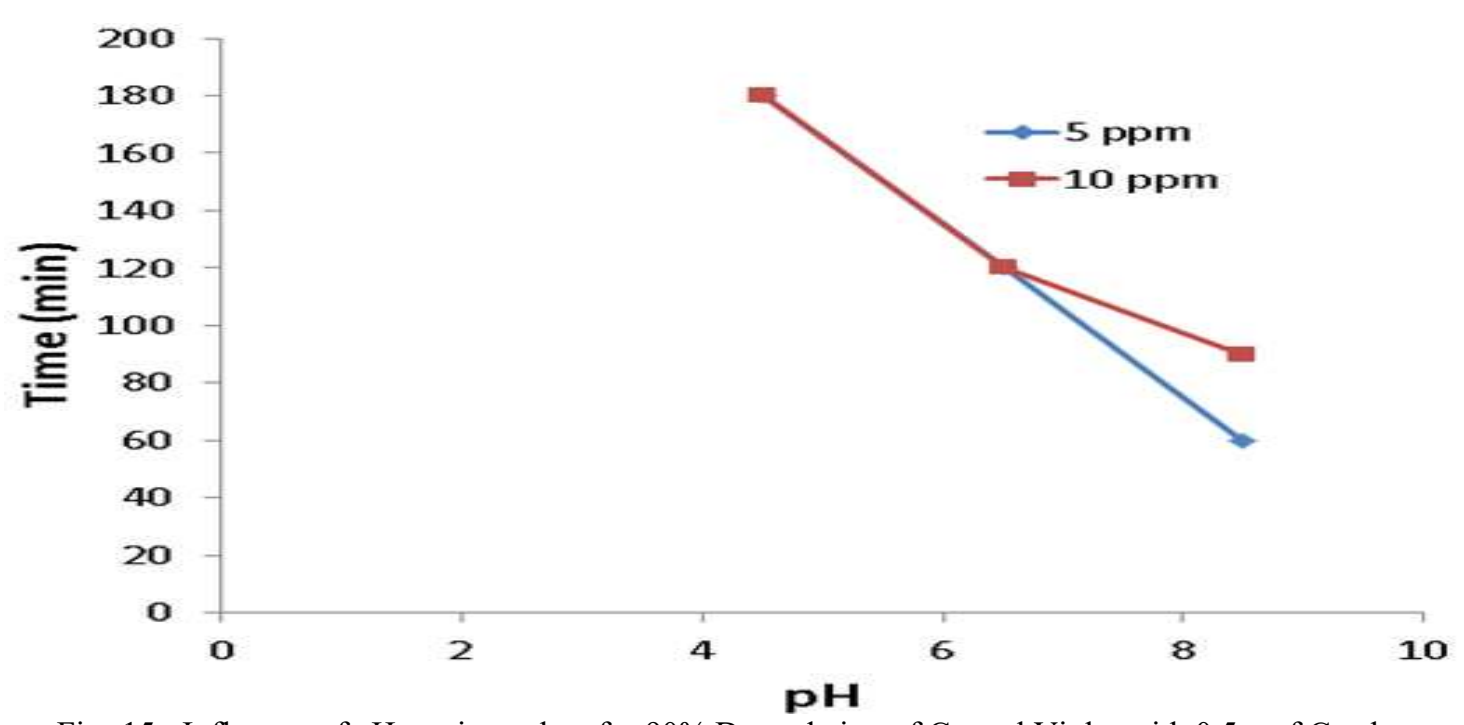

Fig.-15: Influence of $\mathrm{pH}$ on time taken for $90 \%$ Degradation of Crystal Violet with $0.5 \mathrm{~g}$ of Catalyst

Moreover, on increasing the dye concentration from $5 \mathrm{ppm}$ to $15 \mathrm{ppm}$, it was observed that the time duration taken for maximum conversion increases (Fig.-7,8,9 - methylene blue and Fig.-11,12,13 - crystal violet). This can be attributed to the reduction in the availability of several active sites for the adsorption of hydroxyl ions and thereby affecting the hydroxyl radical generation. ${ }^{15-17}$

\section{Influence of $\mathbf{p H}$}

The influence of $\mathrm{pH}$ on the degradation of methylene blue and crystal violet were studied for $5 \mathrm{ppm}$ and $10 \mathrm{ppm}$ concentration by varying the $\mathrm{pH}$ between 4.5 and 8.7 , with a catalyst loading of $0.1 \mathrm{~g}$ (methylene blue) and $0.5 \mathrm{~g}$ (crystal violet). It was found that upon increasing the $\mathrm{pH}$ from 4.5 , the conversion was found to increase and beyond $\mathrm{pH}=8.5$ the activity was found to decrease. Nearly, $98 \%$ conversion was attained within 25 minutes and 45 minutes for $5 \mathrm{ppm}$ and $10 \mathrm{ppm}$ of methylene blue (Fig.-14). Similarly, about $91 \%$ conversion was achieved in 60 and 90 minutes for 5 and $10 \mathrm{ppm}$ of crystal violet (Fig.-15). The surface charge on the zinc oxide can be altered by varying the $\mathrm{pH}$ of the dye solution ${ }^{18-19}$. Under alkaline conditions ( $\mathrm{pH}$ 8.5) the catalyst surface acquires a negative charge and facilitates the effective adsorption of cationic dyes (methylene blue and crystal violet) due to strong electrostatic attraction resulting in an enhanced reaction rate. The stability of the photocatalyst in the selected $\mathrm{pH}$ range is the key factor influencing dye degradation. At lower $\mathrm{pH}(<4.5)$, the conversion decreases due to the dissolution of $\mathrm{Zn}^{+2}$ from $\mathrm{ZnO}$. The higher $\mathrm{pH}(>9)$ value also results in the reduced activity which can be attributed to the competing adsorption of the dye and hydroxyl group on the catalyst surface ${ }^{16}$. Thus, based on the above factors the photocatalytic activity was studied in the $\mathrm{pH}$ range of $4.5-8.7$. The efficiency of the $\mathrm{ZnO} / \mathrm{NaOH}$ was evaluated by employing a similar experimental procedure and considering the following conditions: $\mathrm{pH}-8.5$, dye concentration $-5 \mathrm{ppm}$, catalyst loading $-0.1 \mathrm{~g}$. The results revealed a conversion of $90 \%$ in 55 minutes and the $\mathrm{ZnO} / \mathrm{CAR} / \mathrm{S}$ exhibited only $50 \%$ in 180 minutes. These photocatalysts were found to be less efficient in comparison with the $\mathrm{ZnO} / \mathrm{CAR}$. The reason for the reduced activity can be explained based on the SEM and BET analysis. The SEM image of the $\mathrm{ZnO} / \mathrm{CAR} / \mathrm{S}$ showed non-uniform dispersion and agglomeration with a larger particle size $(70 \mathrm{~nm}$ $80 \mathrm{~nm})$ in comparison with the $\mathrm{ZnO} / \mathrm{CAR}(20 \mathrm{~nm}-30 \mathrm{~nm})$. This is attributed to the fact that during sonication of the suspension, the cavitation and shock waves generated lead to the collisions between particles under high speed ${ }^{20}$. The surface area for the $\mathrm{ZnO} / \mathrm{CAR}, \mathrm{ZnO} / \mathrm{NaOH}$ and $\mathrm{ZnO} / \mathrm{CAR} / \mathrm{S}$ (BET analysis) were found to be $24.8 \mathrm{~m}^{2} / \mathrm{g}, 14.8 \mathrm{~m}^{2} / \mathrm{g}$ and $14.4 \mathrm{~m}^{2} / \mathrm{g}$, respectively. The higher photocatalytic activity of the $\mathrm{ZnO} / \mathrm{CAR}$ can be attributed to the smaller particle size, higher surface area and uniform dispersibility of the zinc oxide particles in comparison to the $\mathrm{ZnO} / \mathrm{NaOH}$ and $\mathrm{ZnO} / \mathrm{CAR} / \mathrm{S}$. The study reveals the role of preparation methods and the precipitating agent in influencing the crystallinity, particle size, shape and surface area of the photocatalyst thus affecting the photocatalytic activity. 
RASĀYAN J. Chem.

Vol. 14 | No. 2 |719-727| April - June | 2021

\section{CONCLUSION}

The degradation of methylene blue and crystal violet were studied using $\mathrm{ZnO}$ photocatalyst prepared using precipitation and sonochemical methods. The catalysts were characterized using XRD, SEM and BET analysis. The XRD analysis proved the formation of $\mathrm{ZnO}$ phase, but the catalyst prepared by precipitation method using ammonium carbonate $(\mathrm{ZnO} / \mathrm{CAR})$ as the precipitant was found to be more crystalline compared to that prepared by other methods. The SEM analysis of $\mathrm{ZnO} / \mathrm{CAR}$ showed smaller particle size and increased surface area compared to $\mathrm{ZnO} / \mathrm{CAR} / \mathrm{S}$ and $\mathrm{ZnO} / \mathrm{NaOH}$. The photocatalytic degradation studies were carried out in a batch reactor in the presence of direct sunlight. The influence of catalyst loading and $\mathrm{pH}$ on dye degradation were studied and optimized. The activity of $\mathrm{ZnO} / \mathrm{CAR}$ catalyst at pH-8.5 with 5 ppm of dye was nearly $98 \%$ conversion $(0.1 \mathrm{~g}$ of catalyst $)$ for methylene blue and $91 \%$ conversion $(0.5 \mathrm{~g}$ of catalyst) for crystal violet, respectively. The smaller particle size and higher surface area were found to be responsible for the higher activity of the $\mathrm{ZnO} / \mathrm{CAR}$ photocatalyst.

\section{REFERENCES}

1. Ogugbue, Chimezie and Sawidis, Thomas, Biotechnology Research International, 967925(2011). DOI: $10.4061 / 2011 / 967925$

2. Preeja. P. Thattil and A. Leema Rose, RASAYAN Journal of Chemistry, 13(2), 1166(2020), DOI: $10.31788 /$ RJC.2020.1325558

3. J. Madhavan, P. Maruthamuthu, S. Murugesan and M. Ashokkumar, Applied Catalysis A, 368, 35(2009), DOI:10.1016/j.apcata.2009.08.008

4. Vaishali Prasad, G. Gnanamani Simiyon, Ansha Elizabeth Mammen and N. Jayaprakash, RASAYAN Journal of Chemistry, 12(2), 860(2019), DOI:10.31788/RJC.2019.1225226

5. A. Kandiel, L. Robben, A. Alkaim and D. Bahnemann, Photochemical \& Photobiological Sciences, 12, 602(2013), DOI:10.1039/C2PP25217A

6. U. Sachin Varma, P. Gautham, D.V. Ravi Kumar, K. M. Sreekanth1, G. Sivasubramanian and K. M. Sreedhar, RASAYAN Journal of Chemistry, 11(4), 1491(2018), DOI:10.31788/RJC.2018.1144000

7. X. Zaier, A. Meftah, A.Y. Jaber, A.A. Abdelaziz, M.S. Aida, Journal of King Saud University Science, 27, 356(2015), DOI:10.1016/j.jksus.2015.04.007

8. S. Balu, K. Uma, G.T. Pan, T. Yang, S. Ramaraj, Materials, 11(6), 1030(2018), DOI: $10.3390 / \mathrm{mal} 1061030$

9. H. Munawaroh, P.L. Sari, S. Wahyuningsih, A.H. Ramelan, AIP Conference Proceedings, 2014, 020119(2018), DOI: 10.1063/1.5054523

10. M. Irani, T. Mohammadi, S, Mohebbi, Journal of the Mexican Chemical Society, 60(4), 218 (2016).

11. T. Begum, P.K. Gogoi, U. Bora, Indian Journal of Chemical Technology, 24, 97(2017).

12. M. Sajid, M., Khan, S. B., Shad, N. A., Amin, N., Z. Zhang, RSC Advances, 8(42), 23489(2018), DOI: $10.1039 /$ C8RA03890B

13. N. Tripathy, R. Ahmad, J.E. Song, H. Park, G. Khang, Material Science, 4, 267(2017), DOI: 10.3934/matersci.2017.1.267

14. S. Lakshmi, R. Renganathan, S.J. Fujita, Journal of Photochemistry and Photobiology A: Chemistry, 88, 163(1995), DOI: 10.1016/1010-6030(94)04030-6

15. K. Byrappa, A. K. Subramani, S. Ananda, K. M. Lokanatha Rai, M. H. Sunitha, B. Basavalingu, K. Soga, Material Science, 41, 1355(2006), DOI:10.1007/s10853-006-7341-x

16. N. Sobana, M. Swaminathan, Separation and Purification Technology, 56, 101(2007), DOI:10.1016/j.seppur.2007.01.032

17. V. Srikant, D.R. Clarke, Journal of Applied Physics, 83, 5447(1998), DOI:10.1063/1.367375

18. E. Haque, J. W. Jun, S.H. Jhung, Jounral of Hazardous Materials, 185, 507(2011), DOI: 10.1016/j.jhazmat.2010.09.035

19. M. N. Patil, A. B. Pandit, Ultrasonics Sonochemistry,14(5), 519(2007), DOI: $10.1016 /$ j.ultsonch.2006.10.007

20. K. S.Suslick, Sonochemistry-Kirk-Othmer Encyclopedia of Chemical Technology. $4^{\text {th }}$ Ed., 26, 516(1998).

[RJC-6176/2020] 